\title{
Review. Huoxetine, orlistat, and sibutramine modestly reduce weight in type 2 diabetes
}

Norris SL, Zhang X, Avenell A, et al. Efficacy of pharmacotherapy for weight loss in adults with type 2 diabetes mellitus: a metaanalysis. Arch Intern Med 2004;164:1395-404.

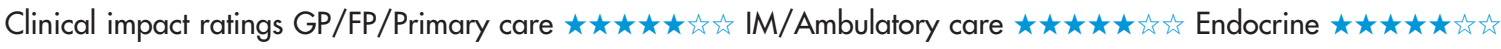

\section{In patients with type 2 diabetes mellitus, what is the efficacy of pharmacotherapy for weight loss?}

\section{METHODS}

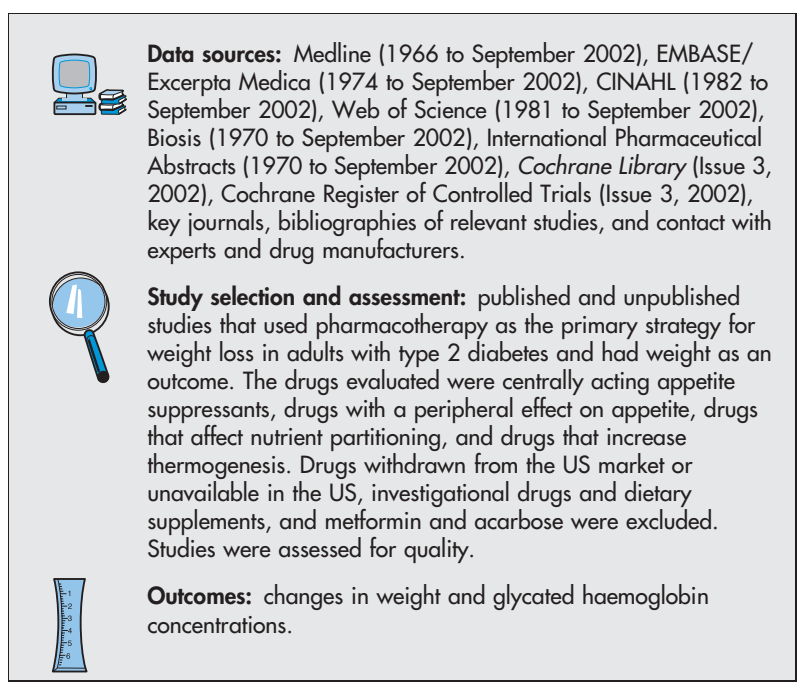

MAIN RESULTS

59 studies met the inclusion criteria. 14 randomised placebo controlled trials $(\mathrm{n}=2231)$ had sufficient data for meta-analysis: 6 of fluoxetine $(\mathrm{n}=296$, mean age 55 y, $51 \%$ women, follow up 8-52 wks), 4 of orlistat ( $n=1475$, mean age 55 y, $52 \%$ women, follow up $52-57$ wks), and 4 of sibutramine $(\mathrm{n}=460$, mean age 53 y, $59 \%$ women; follow up 12-26 wks). Fluoxetine, orlistat, and sibutramine led to modest reductions in weight; and fluoxetine and orlistat led to modest reductions in glycated haemoglobin (table).

\section{CONCLUSION}

In patients with type 2 diabetes mellitus, fluoxetine, orlistat, and sibutramine modestly reduce weight and fluoxetine and orlistat improve blood sugar control.

\section{Abstract and commentary also appear in ACP Journal Club.}

For correspondence: $\operatorname{Dr} \mathrm{S} \mathrm{L}$ Norris, Centers for Disease Control and Prevention, Atlanta, GA, USA. scn5@cdc.gov

Source of funding: Centers for Disease Control and Prevention.

\section{Commentory}

Dof

adwal et al have systematically reviewed the effectiveness and safety of approved anti-obesity medications in clinical trials that lasted for $\geqslant 1$ year for which the results were available by the end of 2002 . Norris et al have done a meta-analysis of studies reported before September 2002 that examined the efficacy of pharmacotherapy for weight loss over 8-57 weeks in adults with type 2 diabetes. Norris et al also report the limited data describing the effects of fluoxetine. More research is needed before the clinical usefulness of this agent can be established. The authors of both reviews conclude that available licensed therapies (eg, sibutramine and orlistat) help induce weight loss. Although of shorter duration, trials of sibutramine suggest that the magnitude of weight reduction is similar to that seen with orlistat.

A number of important questions need to be addressed before advocating widespread use of pharmacological treatments for weight reduction. Norris et al attempted to obtain results of unpublished studies of weight loss treatments but were unable to identify whether publication bias had occurred. It is difficult to infer whether some patients might respond better to certain weight loss therapies because sampling frames, the method of recruitment, and selection of participants were rarely described. Attrition is an important issue in weight loss studies because patients who do not achieve their goal weight often do not return for follow up.

The safety of pharmacological interventions also needs to be considered. Orlistat treatment has been associated with lower concentrations of fat soluble vitamins in plasma. Sibutramine is a similar compound to dexfenfluramine, which has been associated with pulmonary hypertension and valvular heart disease. In the studies reviewed, these serious side effects were not identified. Common side effects were dry mouth, constipation, and insomnia and more rarely palpitations and increased blood pressure. However, sibutramine is contraindicated in people with coronary artery disease, congestive heart failure, arrhythmias, stroke, or inadequately controlled hypertension or those receiving psychiatric medications. These restrictions limit its usefulness in clinical practice.

Both orlistat and sibutramine are associated with improved cardiovascular risk factors. However, it is not known whether treatment with these agents reduces risk of cardiovascular events. Since the work of Padwal et al and Norris et al, 1 other important study in this field has been published. A 4 year, double blind, randomised, prospective trial of 3305 people with $B M I \geqslant 30 \mathrm{~kg} / \mathrm{m}^{2}$ who were randomised to lifestyle intervention plus either orlistat, $120 \mathrm{mg} 3$ times daily, or placebo showed that orlistat treatment combined with lifestyle changes reduced incident diabetes by $37 \%{ }^{.}$It is uncertain if treatment with drugs, such as orlistat or sibutramine, is associated with weight cycling, which appears to adversely affect cardiovascular risk factors.

Commentary continued on next page.

Pharmacotherapy for weight reduction in type 2 diabetes*

\begin{tabular}{|c|c|c|c|c|}
\hline Comparisons & Outcomes & Follow up & Number of trials $(\mathrm{n})$ & Weighted mean difference $(95 \% \mathrm{Cl})$ \\
\hline \multirow[t]{4}{*}{ Fluoxetine $v$ placebo } & Weight (kg) & $8-16$ wks & $5(192)$ & $-3.4(-5.2$ to -1.7$)$ \\
\hline & Weight (kg) & $24-30$ wks & $4(97)$ & $-5.1(-6.9$ to -3.3$)$ \\
\hline & $\mathrm{GHb}$ & $8-16$ wks & $4(145)$ & $-1.0 \%(-1.5$ to -0.4$)$ \\
\hline & $\mathrm{GHb}$ & $24-30$ wks & $4(97)$ & $-1.0 \%(-1.4$ to -0.6$)$ \\
\hline \multirow[t]{2}{*}{ Orlistat $v$ placebo } & Weight (kg) & $52-57$ wks & $3(818)$ & $-2.6(-3.2$ to -2.1$)$ \\
\hline & $\mathrm{GHb}$ & $52-57$ wks & $4(904)$ & $-0.4 \%(-0.5$ to -0.3$)$ \\
\hline \multirow[t]{2}{*}{ Sibutramine $v$ placebo } & Weight $(\mathrm{kg})$ & $12-26$ wks & $4(391)$ & $-4.5(-7.2$ to -1.8$)$ \\
\hline & $\mathrm{GHb}$ & $12-26$ wks & $4(368)$ & $-0.7 \%(-1.9$ to 0.5$) \dagger$ \\
\hline
\end{tabular}

${ }^{*} \mathrm{GHb}=$ glycated haemoglobin. $\mathrm{Cl}$ defined in glossary; data were pooled using a random effects model. Differences favour the active drug. †Not significant. 